\title{
SENYAWA DISOBININ YANG BERSIFAT ANTIMALARIA DARI BIJI TUMBUHANChisocheton macrophyllus (MELIACEAE)
}

\author{
Nurlelasari, Desi Harneti PH, Tri Mayanti, dan Unang Supratman \\ Departemen Kimia,Fakultas Matematika dan Ilmu Pengetahuan Alam, \\ Universitas Padjadjaran \\ E-mail: nurlelasari@unpad.ac.id
}

\begin{abstract}
Disobinin compounds have been isolated from the seeds Chisocheton macrophyllus ( Meliaceae). The chemical structure of compounds disobinin identified based on data covering UV spectroscopy, IR, ID-NMR, 2D-NMR and mass spectra as well as the comparison with the data obtained from the literature. Disobinin compound showed antimalarial effect against $P$. falcifarum with $I C_{50}$ values from 0.001 to $0.01 \mu \mathrm{g} / \mathrm{mL}$. Limonoids compound, disobinin reported for the first time in the genus of Chisocheton.
\end{abstract}

Keywords: Meliaceae, Chisocheton macrophyllus, disobinin, limonoids, antimalarial.

\section{PENDAHULUAN}

Tumbuhan Meliaceae memiliki 51 genus dan 550 spesies yang terdistribusi di negara subtropik dan ropikal. Tumbuhan telah dikenal sebagai tumbuhan penghasil senyawa-senyawa yang memiliki aktivitas antimalaria dan senyawa insektisida, antiviral, antioksidan, antikanker, antibakteri, antimikroba dan antiimflammasi (Heyne, 1987). Beberapa senyawa aktif yang telah berhasil diisolasi dari Meliaceae, seperti azadirachtin (A. indica) yang bersifat insektisida alami dan sudah dipasarkan sebagai insektisida botani di Amerika Serikat dan India (Wong et al., 2011; Parmar,1995). Dari biji Lansium domesticum Corr dilaporkan mengandung triterpenoid lansiolida yang memiliki aktivitas antimalaria baik secara in vitro maupun secara in vivo (Omar et al., 2003). Dari spesies A. indica dan Cedrela odorata diketahui mengandung limonoid gedunin yang memiliki aktivitas antimalaria tiga kali lebih kuat dari klorokuinin tetapi dua puluh kali lebih lemah dari kuinin (Bray et al., 1990). Beberapa spesies tumbuhan ini telah dipergunakan secara tradisional sebagai obat pencuci perut, bahan obat dan kosmetika serta banyak dimanfaatkan sebagai racun pada ikan (Lim, 2008). Kandungan senyawa pada genus Chisocheton telah banyak dilaporkan memiliki aktivitas yang sangat bermanfaat baik dalam bidang kesehatan maupun pertanian, diantaranya sebagai antimalaria, antimikrobakteri, sitotoksik (Maneerat et al., 2008; 
Phongmaykin et al., 2008; Mohamad et al., 2009;), sitotoksik (Wong et al., 2011; Mohamad et al., 2008; Awang et al., 2007), antitumor (Yang et al., 2009) dan antiinflamasi (Yang et al., 2011).

Inada et al. (1993) melaporkan bahwa dari daun Chisocheton macrophyllus (Meliaceae) ditemukan satu senyawa triterpenoid yang memiliki aktivitas antitumor yaitu 24- hidroksidamara -20,25-dien-3-on, dan 3 senyawa triterpenoid yang sudah dikenal yaitu asam moronat, asam oleanolat dan asam betulonat. Dalam penelitian berkelanjutan kami terhadap pencarian senyawa bioaktif dari tumbuhan Chisocheton Indonesia, telah dilakukan penelitian pendahuluan terhadap ekstrak etil asetat dari biji C. macrophyllus memiliki aktivitas antimalaria dengan nilai $0,01-0,1 \mu \mathrm{g} / \mathrm{mL}$ terhadap $P$. falciparum galur 3D7. Hal ini menjadi petunjuk bahwa biji tumbuhan Chisocheton Indonesia, $C$. Macrophyllus memiliki potensi besar ditemukannya senyawa-senyawa yang beraktivitas antimalaria.Pada komunikasi ini kami akan menjelaskan isolasi, identifikasi struktur senyawa limonoid, disobinin yang beraktivitas antimalaria terhadap P. falciparum galur 3D7.

\section{METODE PENELITIAN}

Alat

Titik leleh diukur dengan peralatan titik leleh Fisher-John (tidak terkoreksi). Spektra IR diperoleh dari spektrofotometer FTIR spectrum One Perkin Elmer pada KBr. Spektra ${ }^{1} \mathrm{H}$-dan ${ }^{13} \mathrm{C}-\mathrm{NMR}$ diperoleh dengan spektrometer JEOL JNM ECA-500. Spektra MS diperoleh dengan Mariner Biospectrometry-Finnigan instrument. Pemisahan kromatografi dilakukan pada silika gel G60, silika gel (70-230 dan 200-400 mesh, Merck). KLT plat diisi dengan silika gel GF254 (Merck, 0,25 mm) dan deteksi di lakukan dengan penampak noda $10 \% \mathrm{H} 2 \mathrm{SO} 4$ dalam etanol diikuti dengan pemanasan.

\section{Bahan}

Biji C. macrophyllus diperoleh dari Kebun Raya Bogor, Jawa Barat padabulan September 2011. Tumbuhan ini dideterminasidi Herbarium Bogoriense, Pusat penelitian Biologi,LIPI, Bogor dan contoh specimen (No. Bo-1295453)tersimpan di Herbarium tersebut.

\section{Prosedur Kerja}

Serbuk biji C. macrophyllus (3,5 kg) kering dihaluskan, diekstraksi menggunakan teknik maserasi (ekstraksi padat-cair) dengan pelarut $n$-heksan, etil asetat, dan metanol padasuhu ruangan. Maserat etil asetat dipekatkan dengan rotary evaporator sehingga didapatkan ekstrak $n$-heksan $(60 \mathrm{~g})$, 
selanjutnya dipisahkan dengan teknik kromatografi cair vakum dengan fase diam silika geldan fase gerak campuran pelarut berupa $n$-heksan,etil asetat, metanol; $10 \%$, secara bergradien sehingga yang selanjutnya direkristalisasi pada suhu ruangan menggunakan pelarut $n$-heksan dan diperoleh padatan murni $(10,6 \mathrm{mg})$. Seluruh tahapan pemisahan dipantau dengan kromatografi lapis tipis di bawah sinar UV pada panjang gelombang $254 \mathrm{~nm}$ dan $365 \mathrm{~nm}$. Isolat murni FB4 tersebut dielusidasi strukturnya dengan metode spektroskopi UV, IR, 1DNMR, 2D-NMR dan massa dan ditetapkan sebagai senyawa disobinin.

\section{HASIL DAN PEMBAHASAN}

Disobinin diperoleh sebagai padatan berupa kristal bening dengan titik leleh sebesar $194-197^{\circ} \mathrm{C}$. Rumus senyawa disobinin ditetapkan sebagai $\mathrm{C}_{30} \mathrm{H}_{38} \mathrm{O}_{6}$ berdasarkan spektrum massa HR-ESI-TOFMS $(\mathrm{m} / \mathrm{z} \quad 494,2668$ $[\mathrm{M}+\mathrm{H}]^{+}$), bersama dengan data NMR (Tabel 1), dengan demikian senyawa disobinin memiliki 7 derajat ketidakjenuhan. Spektra (metanol) menunjukkan serapan pada $\lambda_{\text {maks }} 240 \mathrm{~nm}$ ( $\varepsilon$ 28.911), menunjukkan adanya sistem keton terkonjugasi tak jenuh- $\alpha, \beta$. Spektrum IR menunjukkan serapan untuk gugus $C$ $\mathrm{H}$ alifatik $\left(v_{\text {maks }} 2938 \mathrm{~cm}^{-1}\right)$, olifenik terisolasi $\left(v_{\text {maks }} 1503 \mathrm{~cm}^{-1}\right)$, karbonil ester $\left(v_{\text {maks }} 1667 \mathrm{~cm}^{-1}\right)$,eter $\left(v_{\text {maks }} 1249 \mathrm{~cm}^{-1}\right)$, dan gugus gem-dimetil $\left(v_{\text {maks }} 1363 \mathrm{~cm}^{-}\right.$ $\left.{ }^{1}\right)$.

Spektrum ${ }^{13} \mathrm{C}-\mathrm{NMR}$ menunjukkan adanya 30 sinyal karbon yang diperinci dengan percobaan DEPT dan HMQC sebagai satu karbonil pada $\delta_{\mathrm{C}}$ (ppm) 204,1(C-3), dua karbon asetil pada $\delta_{\mathrm{C}}(\mathrm{ppm}) 21,3$ (C-1'), 22,4(C-2'), $170,6\left(\mathrm{C}-1^{\prime \prime}\right)$ dan 170,6 (C-2"), enam karbon $\mathrm{sp}^{2}$ pada $\delta_{\mathrm{C}}(\mathrm{ppm}) 112,0(\mathrm{C}-22)$, 120,2 (C-15), 126,6 (C-2), 140,9 (C-21), 143,7 (C-23), dan 158,2 (C-1), lima metil $\mathrm{sp}^{3}$, tiga metilen $\mathrm{sp}^{3}$, dua karbon teroksigenasi $\mathrm{sp}^{2}$ pada $\delta_{\mathrm{C}} 70,0(\mathrm{C}-6)$ dan 75,1 (C-7), lima metin $\mathrm{sp}^{3}$, dan empat karbon kuarterner $\mathrm{sp}^{3}$. (Tabel 1). Fungsionalitas ini dihitung sebagai tujuh dari total dua belas derajat ketidakjenuhan, lima derajat ketidakjenuhan tersisa sesuai dengan kerangka limonoid pentasiklik (Wong et al., 2011). Dugaan kerangka pentasiklik dengan gugus asetil sebagai substituennya dikuatkan dengan spektrum ${ }^{1} \mathrm{H}-\mathrm{NMR}$. Diketahui terdapat sinyal yang menunjukkan adanya karakteristik proton dari lima metil tersier pada $\delta_{\mathrm{H}} 1,15 ; 1,22 ; 1,22 ; 1,22 ; 1,35$ (masing-masing $3 \mathrm{H}$, singlet), dua gugus asetil $\left(\delta_{\mathrm{H}} 21,3 ; 22,4\right)$, dua proton teroksigenasi pada $\delta_{\mathrm{H}}$ [5,40 dan 5,40 (masing-masing $1 \mathrm{H}, \mathrm{m})]$, sinyal furan pada $\delta_{\mathrm{H}}[7,40(1 \mathrm{H}, \mathrm{s})$, $6,40(1 \mathrm{H}, \mathrm{s})$ dan $7,50(1 \mathrm{H}, \mathrm{s})]$, dan dua proton olefinik pada $\delta_{\mathrm{H}}[5,84(1 \mathrm{H}, \mathrm{d}$, $J=10,3 \mathrm{~Hz})$ dan 7,3 $(1 \mathrm{H}, \mathrm{d}, J=10,3 \mathrm{~Hz})$ ] sehingga dapat diduga struktur kimia senyawa adalah disobinin dengan gugus asetil yang terikat pada kerangkanya. 


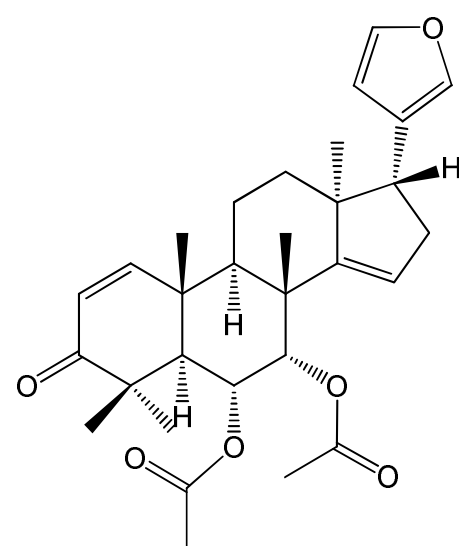

a

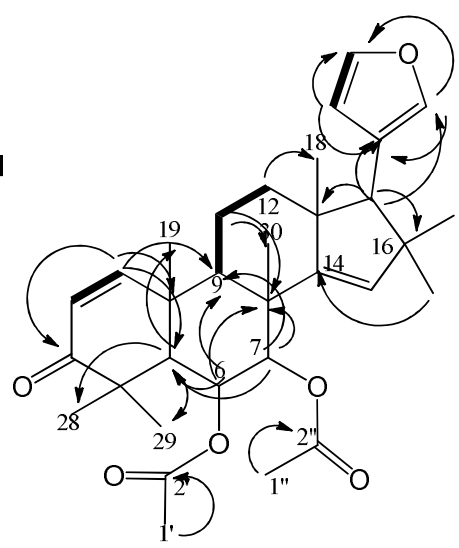

b

Gambar 1. Struktur Kimia Disobinin (a) dan Korelasi $\operatorname{HMBC}(500 \mathrm{~Hz})(b)$

Untuk menentukan posisi gugus metil tersier, gugus asetil dan olefinik pada disobinin, percobaan COSY dan HMBC dilakukan dan hasilnya dapat dilihat pada Gambar 2. Pada spektrum HMBC, korelasi dari proton metil tersier terhadap karbon tetangganya dapat menjelaskan keberadaan tujuh metil tersier pada disobinin. Dua proton asetil pada $\delta_{\mathrm{H}} 2,00\left(\mathrm{H}-1^{\prime}\right)$ dan $\delta_{\mathrm{H}} 2,00\left(\mathrm{H}-1^{\prime \prime}\right)$ saling terjodoh satu sama lain, proton metin pada $\delta_{\mathrm{H}} 5,40(\mathrm{H}-7)$ berkorelasi tiga ikatan $\left({ }^{3} J\right)$ dengan C-9 $\left(\delta_{\mathrm{C}} 38,3\right)$, karbon metin pada C-5 $\left(\delta_{\mathrm{C}} 48,9\right)$ dan karbon kuarterner pada C-8 $\left(\delta_{C} 43,9\right)$ menyarankan bahwa gugus asetil terikat pada C-6 dan C-7. Dua proton olefinik pada $\delta_{\mathrm{H}} 7,30(\mathrm{H}-1)$ saling terjodoh tiga ikatan $\left({ }^{3} \mathrm{~J}\right)$ dengan karbon kuarterner pada C-3 $\left(\delta_{\mathrm{C}} 204,1\right)$ dan proton metilen pada $\delta_{\mathrm{H}} 1,73$ dan 1,93 $(\mathrm{H}-16)$ saling terjodoh tiga ikatan $\left({ }^{3} J\right)$ dengan karbon kuarternerC-14 $\left(\delta_{\mathrm{C}} 159,7\right)$ menyarankan posisi gugus olefinik terletak pada C-1 dan C-2 $\left(\Delta^{1,2}\right)$ serta C-14 dan $\mathrm{C}-15\left(\Delta^{14,15}\right)$. Proton metin pada $\delta_{\mathrm{H}} 2,84$ dan $7,40(\mathrm{H}-17)$ saling terjodoh dua ikatan $\left({ }^{2} J\right)$ dengan karbon metilen pada C-16 $\left(\delta_{\mathrm{C}} 33,6\right)$ dan karbon kuarterner pada C-13 $\left(\delta_{\mathrm{C}} 47,9\right)$ dan C-20 $\left(\delta_{\mathrm{C}} 125,5\right)$ menyarankan posisi gugus furan terikat pada $\mathrm{C}-17$. Perbandingan data NMR disobinin dengan senyawa limonoid yang ditemukan pada C. siamensis (Laphookhieo et al., 2008) menunjukkan kesesuaian yang tinggi, sehingga dengan demikian diidentifikasikan sebagai disobinin. Senyawa disobinin diuji aktivitas antimalaria terhadap $P$. falciparum galur 3D7 dengan nilai $0,001-0,01 \mu \mathrm{g} / \mathrm{mL}$. 
Nurlelasari, Desi Harneti PH, Tri Mayanti, dan Unang Supratman Senyawa Disobinin yang Bersifat Antimalaria dari Bïi Tumbuhan Chisocheton macrophyllus

Tabel 1. Data NMR Disobinin

\begin{tabular}{|c|c|c|}
\hline Posisi C & $\begin{array}{c}{ }^{1} \mathrm{H}-\mathrm{NMR} \\
\delta \mathrm{H} \text { ppm }(\Sigma \mathrm{H} ; \\
\text { mult; } J=\mathrm{Hz})\end{array}$ & $\begin{array}{l}{ }^{13} \mathrm{C}-\mathrm{NMR} \\
\delta \mathrm{C} \text { ppm }\end{array}$ \\
\hline 1 & $7,3 \quad(1 \mathrm{H} ; \mathrm{d} ; 10,3)$ & $158,2(d)$ \\
\hline 2 & $5,84(1 \mathrm{H} ; \mathrm{d} ; 10,3)$ & $126,6(d)$ \\
\hline 3 & - & $204,1(d)$ \\
\hline 4 & - & $45,6(\mathrm{~s})$ \\
\hline 5 & $2,5 \quad(1 \mathrm{H} ; \mathrm{m})$ & $48,9(\mathrm{~d})$ \\
\hline 6 & $5,40(1 \mathrm{H} ; \mathrm{m})$ & $70,0(\mathrm{t})$ \\
\hline 7 & $5,40(1 \mathrm{H} ; \mathrm{m})$ & $75,1(d)$ \\
\hline 8 & - & $43,9(\mathrm{~s})$ \\
\hline 9 & $1,28(1 \mathrm{H} ; \mathrm{m})$ & $38,3(d)$ \\
\hline 10 & - & $41,6(s)$ \\
\hline 11 & $1,80(1 \mathrm{H} ; \mathrm{m})$ & $17,0(t)$ \\
\hline 12 & $\begin{array}{l}2,3 \quad(1 \mathrm{H} ; \mathrm{m}) ; 2,5 \\
(1 \mathrm{H} ; \mathrm{m})\end{array}$ & $35,3(\mathrm{t})$ \\
\hline 13 & - & $47,9(\mathrm{~s})$ \\
\hline 14 & - & $159,7(\mathrm{~s})$ \\
\hline 15 & $2,26(1 \mathrm{H} ; \mathrm{m})$ & $120,2(\mathrm{~s})$ \\
\hline & $1,73 \quad(1 \mathrm{H} ; \quad \mathrm{m})$ & $33,6(\mathrm{t})$ \\
\hline 16 & $1,93(1 \mathrm{H} ; \mathrm{m})$ & \\
\hline 17 & $\begin{array}{l}2,84(1 \mathrm{H} ; \mathrm{dd} ; 7,4 \\
11,3)\end{array}$ & $52,7(\mathrm{~d})$ \\
\hline 18 & $1,35(3 \mathrm{H} ; \mathrm{s})$ & $27,1(q)$ \\
\hline 19 & $1,22(3 \mathrm{H} ; \mathrm{s})$ & $32,1(q)$ \\
\hline 20 & - & $125,5(\mathrm{~s})$ \\
\hline 21 & $7,40(1 \mathrm{H} ; \mathrm{s})$ & $140,9(d)$ \\
\hline 22 & $6,40(1 \mathrm{H} ; \mathrm{s})$ & $112,0(d)$ \\
\hline 23 & $7,50(1 \mathrm{H} ; \mathrm{s})$ & $143,7(d)$ \\
\hline 28 & $1,15(3 \mathrm{H} ; \mathrm{s})$ & $20,7(q)$ \\
\hline 29 & $1,22(3 \mathrm{H} ; \mathrm{s})$ & $20,9(q)$ \\
\hline 30 & $1,22(3 \mathrm{H} ; \mathrm{s})$ & $21,2(q)$ \\
\hline $1^{\prime}$ & $2,00(3 \mathrm{H} ; \mathrm{s})$ & $21,3(q)$ \\
\hline $1 "$ & - & $170,6(\mathrm{~s})$ \\
\hline $2^{\prime}$ & $2,00(3 \mathrm{H} ; \mathrm{s})$ & $22,4(q)$ \\
\hline $2 "$ & - & $170,6(\mathrm{~s})$ \\
\hline
\end{tabular}




\section{PENUTUP}

\section{Kesimpulan}

Berdasarkan hasil interpretasi spektrum UV, IR, MS, ${ }^{1} \mathrm{H}-\mathrm{NMR},{ }^{13} \mathrm{C}-$ NMR, DEPT, HMQC, HMBC, ${ }^{1} \mathrm{H}^{-1} \mathrm{HCOSY}$ dan data-data pembanding, isolat berupa berupa kristal bening sebanyak $10,6 \mathrm{mg}$ yang diisolasi dari 3,5 $\mathrm{kg}$ serbuk biji $C$. macrophyllus ditetapkan sebagai senyawa limonoid yaitu disobinin yang memiliki aktivitas antimalaria terhadap $P$. falciparum galur 3D7 dengan nilai $0,001-0,01 \mu \mathrm{g} / \mathrm{mL}$. Senyawa disobinin ini baru pertama kali dilaporkan dari tumbuhan C. macrophyllus.

\section{Ucapan Terima Kasih}

Terima kasih disampaikan kepada Direktorat Jenderal Pendidikan Tinggi, Kementerian Pendidikan dan Kebudayaan, Indonesia atas dana Penelitian Hibah Kompetitif Unpad (2011-2012). Terimakasih kami sampaikan Prof. Yoshihito Shiono, Department of Bioresource Engineering, Faculty of Agriculture, Yamagata University, Japan atas pengukuran HR-ESI-TOFMS. Terima kasih juga kami sampaikan kepada Dr. Ahmad Darmawan dan Sofa Fajriyah, M.Si, Pusat PenelitianKimia LIPI Serpong, atas pengukuran spektrum NMR. Terima kasih Dr. Wiwied Ekasari, M.Si., Apt. Fakultas Farmasi, Laboratorium Farmakognosi dan Fitokimia, Universitas Airlangga, Surabaya atas pengukuran aktivitas antimalaria terhadap Plasmodium falciparum galur FCR-3/A2.

\section{DAFTAR PUSTAKA}

Awang, K., Lim, C.S., Mohamad K., Morita, H., Hirasawa, Y., Takeya, K., Thoison, O.,and Hadi, A.H.A., 2007, Erythrocarpines A-E, new cytotoxic limonoids from Chisochetonerytrocarpus, Bioorg Med Chem, 15:5997-6002.

Bray, D.H., Warhurst, D.C., Conolly, J.D., O’Neil, M.J., and Philipson, J.D., 1990, Plants as source of antimalarial drug. Pt. 7 activity of some species Meliaceae plants and their constituent limonoids. Phytother Res, 4:29-35.

Heyne, K., 1987,The Useful Indonesian Plants, Research and Development Agency, Ministry of Forestry, Jakarta Indonesia.

Inada, A., Sukemawa, M., Murata, H., Nakanishi, T., Tokuda, H., Nishino, H., Iwashima, A., Darnaedi, D., and Murata, J.,1993, Phytochemical studies on Maleaceous Plant. Part VIII. Structures and Inhibitory Effects on Epstein-Barr Virus Activation of Triterpenoids from Leaves of Chisocheton macrophyllus King,Chem Pharm Bull, 41: 617-619. 
Laphookhieo, S., Maneerat, W., Koysomboon, S., Kiattansakul, R., Chantrapromma, K., and Syers, J.K., 2008. A Novel Limonoid from the seeds of Chisocheton siamensis,Can J Chem,86: 205-208.

Maneerat, W., Laphookhieo, S., Syers, J.K., Kiattansakul., Koysomboon, S., and Chantrapromna, K., 2008, Antimalaria, Antimicobacterial and Cytotoxic limonoid from Chisocheton siamensis, Phytomedicine,15: 1130-1135.

Mohamad, K., Hirasawa,Y., Lim C.S., Awang, K., Hamid, A., Hadi, A., Takeya, K., and Morita, H.,2008, Ceramicines A and walsogyne A novel limonoids from two species of Meliaceae,Tetrahedron Letter, 49: 42764278 .

Mohamad, K., Hirasawa,Y., Litaudon, M., Awang, K., Hamid, A., Hadi, A., Takeya, K., Ekasari, W., Widyawaruyanti, A., Zaini, N.C., and Morita, H.,2009,Ceramicines B-D, new antiplasmodial limonoids from Chisocheton ceramicus,Bioorganic \& Medicinal Chemistry, 17: 727730 .

Omar, S., Zhang, J., MacKinnon, S., Leaman, D., Durst, T., Philogene, BJ., Anarson, JT., Sanchez- Vindas, PE., Poveda, L., Tamez, PA., and Pezzuto, JM., 2003, Traditionally-used antimalarials from Meliaceae,Curr Top Med Chem,3(2): 133-9.

Parmar, B.S., 1995, Results with commercial neem formulations produced in India. In H. Schmutterer (ed.), The neem tree Azadirachtaindica A. Juss. And other Meliaceous plants. Sources of unique natural products for integrate pest managemant, medicine, industry and other purposes, VCH Tokyo, pp. 453-470.

Phongmaykin, J., Kumamoto, T., Ishikawa, T., Suttisri,R,,and Saifah, E., 2008. A New Sesquiterpene and Other Terpenoid Constituents of Chisochetonpenduliflorus,Arch Pharm Res,31: 1.

Wong, C.P., Shimada, M., Nagakura, Y., Nugroho, A.E., Hirasawa, Y., Kaneda, T., Awang, K., Hamid, A., Hadi, A., Mohamad, K., Shiro, M., and Morita, H., 2011, Ceramicines E-I, New Limonoids from Chisocheton ceramicus,Chem Farm Bull,59: 407-411.

Yang, MH., Wang, JS., Luo, JG., Wang, XB., and Kong, LY., 2009, Tetranortriterpenoids from Chisocheton paniculatus,Journal Nat Pro, 72: 2014-2018.

Yang, M.H., Wang J.S., Luo J.G., Wang X.B.,and Kong L.Y., 2011, Chisopanins A-K, 11 New newprotolimonoids from Chisocheton paniculatus and their anti-inflammatory activities, Bioorganic \& Medicinal Chemistry,19: 1409-1417. 